\title{
Prevalence of Intestinal Parasitic Infections at a Tertiary Care Hospital: A Retrospective Study
}

\author{
M. Ravish Kumar ${ }^{1}$, Praveen Kumar Doddamani ${ }^{{ }^{*} \text {, }}$ \\ Prashant Parandekar ${ }^{1}$ and Prashant Kumar ${ }^{2}$
}

${ }^{1}$ Department of Microbiology, ${ }^{2}$ Department of Community Medicine, ESIC medical College, Gulbarga, Karnataka 585105, India

*Corresponding author

\begin{tabular}{|c|c|}
\hline & A B S T R A C T \\
\hline & \multirow{5}{*}{$\begin{array}{l}\text { Intestinal parasitic Infections are one of the major health problems in developing countries } \\
\text { like India. The prevalence of different parasitic infections varies from one place to another } \\
\text { and depends on many factors such as socio-economic status, hygiene, water supply, } \\
\text { sanitation, population density, nutritional status and climatic conditions. This was a } \\
\text { retrospective study conducted from January } 2017 \text { to December } 2018 \text { at a tertiary care } \\
\text { hospital, Kalaburagi which is a dry, hot place. Stool samples sent from different } \\
\text { departments irrespective of age were included in the study. Sample was collected in wide } \\
\text { mouthed sterile screw capped and was subjected to routine macroscopic and microscopic } \\
\text { examination. A total of } 726 \text { stool specimens were examined for probable parasitic } \\
\text { infection. The prevalence of Intestinal parasitic Infections at our hospital was } 8.12 \% \text {. The } \\
\text { parasites detected was Entamoeba histolytica (55.93\%), Giardia lamblia (27.12\%), } \\
\text { Hymenolepis nana (5.08\%), Ascaris lumbricoides (3.39\%), Strongyloides stercoralis } \\
\text { (3.39\%), Taenia species (3.39\%), Enterobius vermicularis (1.70\%). The present study } \\
\text { highlights the importance of knowledge of intestinal parasitic infections of particular } \\
\text { region, which help the clinicians for diagnosis and management. Prevalence rate in our } \\
\text { study was low which indicates that there is improvement in personal hygiene, drinking } \\
\text { water supply and sanitary practices. }\end{array}$} \\
\hline $\begin{array}{l}\text { Intestinal parasitic } \\
\text { infections, Ascaris, } \\
\text { Stool samples }\end{array}$ & \\
\hline Article Info & \\
\hline $\begin{array}{l}\text { Accepted: } \\
\text { 15 May } 2019 \\
\text { Available Online: } \\
10 \text { June } 2019\end{array}$ & \\
\hline & \\
\hline
\end{tabular}

\section{Introduction}

One of the major health problems in developing countries like India is Intestinal Parasitic Infections (IPI's). It is estimated that about $15-20 \%$ of world's population is suffering from parasitic infection. Overall prevalence in India ranges from $12.5 \%$ to $66 \%$. The prevalence of different parasitic infection varies from one place to another and depends on many factors such as socio- economic status, hygiene, water supply, sanitation, population density, nutritional status and climatic conditions. ${ }^{1}$ The transmission of parasitic infection takes place by ingestion, penetration of intact skin and rarely by inhalation of infective forms. ${ }^{2}$ These infections are more common in children and can lead to nutritional deficiencies, anemia, impaired learning, and growth retardation. ${ }^{1}$ The most important drawback of IPI's is that about $90 \%$ of infected individuals remain 
asymptomatic. ${ }^{3}$ The most common parasitic infestations reported globally are Ascaris (20\%), Ancylostoma duodenale (18\%), Trichuris trichiura (10\%), and Entamoeba histolytica $(10 \%){ }^{4} \quad$ Studies have been conducted in this region in the past about 8-10 yrs back with prevalence of $27.6 \%$ (Parameshwarappa et al., $)^{5}$. Though ours is a similar study, we wanted to know the present prevalence and change in the trend of infection. The objective of the study was to know the prevalence of intestinal parasitic infections at a tertiary care hospital by collecting retrospective data.

\section{Materials and Methods}

This is a retrospective study which was conducted at Microbiology laboratory, ESIC hospital, Kalaburagi. The data of last two years was collected i.e. from January 2017 to December 2018. Stool samples sent from different departments irrespective of age were included in the study.

Sample was collected in wide mouthed sterile screw capped, labelled containers without preservative. All faecal samples were subjected to routine macroscopic and microscopic examination.

For microscopic examination, saline wet mount and Lugol's iodine wet mount was prepared

The stool specimen was examined by

1. Macroscopic examination: The colour, consistency, presence of mucus and the nature of the faeces were recorded. The stool specimens were examined for the presence of adult forms of the helminths either with the naked eye or with the aid of a hand lens.

2. Direct microscopic examination by using saline and iodine preparations: On a $1 \mathrm{~mm}$ thick microscopic slide, a small amount of stool sample was emulsified in 1-2 drops of saline or iodine solution. A cover slip was placed on it by taking care that the preparation was free of air bubbles and macroscopic debris observed under low (10x) and high (40x) power.

\section{Results and Discussion}

A total of 726 stool samples were examined, out of which $59(8.12 \%)$ were found to be positive for parasites. (Graph 1)

The parasites detected in decreasing frequency were Entamoeba histolytica, Giardia lamblia, Hymenolepis nana, Ascaris lumbricoides, Strongyloides stercoralis, Taenia species, Enterobius vermicularis (Table 1; Graph 2).

Among the parasites detected, protozoa $(83.05 \%)$ were more compared to helminths $(16.95 \%)$. The parasites with highest number were Entamoeba histolytica followed by Giardia lamblia and Hymenolepis nana.

Most of the Entamoeba histolytica infections $(n=20)$ were seen in adults and $(n=13)$ in children (Figure 9 and 10).

Among 16 cases of Giardia lamblia infection, 13 cases were seen in children, age ranging from 8 months to $10 \mathrm{yrs}$.

Three cases of Giardia lamblia infection showed only trophozoites (Figure 2), 3 cases showed both cysts and trophozoites and rest 10 showed only cysts (Figure 11).

All the 3 Hymenolepis nana infection (Figure 4) and 2 Ascaris lumbricoides infection were seen in school going children (Figure 7 and 8).

The Taenia species (Taenia saginata) was identified based on morphology of the gravid segment and history of consumption of beef 
(Figure 5 and 12). Two Strogyloides stercoralis larval forms were identified from stool specimen (Figure 1). Enterobius vermicularis adult worm and eggs (Figure 6 and 3) were identified by taking National Institute of Health (NIH) swab from 6yr old child who had severe pruritis ani.

Table.1 Distribution of different intestinal parasitic infections

\begin{tabular}{|l|c|l|}
\hline Parasite & Number of Positives & Percentage (\%) \\
\hline Entamoeba histolytica & 33 & 55.93 \\
\hline Giardia lamblia & 16 & 27.12 \\
\hline Hymenolepis nana & 03 & 5.08 \\
\hline Ascaris lumbricoides & 02 & 3.39 \\
\hline Strogyloides stercoralis larva & 02 & 3.39 \\
\hline Taenia species (Proglottid and eggs) & 02 & 3.39 \\
\hline Enterobius vermicularis (Adult worm and eggs) & 01 & 1.70 \\
\hline
\end{tabular}

Table.2 Age wise distribution of intestinal parasitic infections

\begin{tabular}{|l|c|c|c|c|c|}
\hline & \multicolumn{5}{|c|}{ Age (Years) } \\
\hline Parasite & $0-20$ & $20-40$ & $40-60$ & $60-80$ & $>80$ \\
\hline Entamoeba histolytica & 13 & 9 & 6 & 04 & 01 \\
\hline Giardia lamblia & 13 & 2 & 0 & 01 & 0 \\
\hline Hymenoiepis nana & 03 & 0 & 0 & 0 & 0 \\
\hline Ascaris lumbricoides & 02 & 0 & 0 & 0 & 0 \\
\hline Strongyloides stercoralis & 0 & 2 & 0 & 0 & 0 \\
\hline Taenia species & 0 & 0 & 02 & 0 & 0 \\
\hline Enterobius vermicularis & 01 & 0 & 0 & 0 & 0 \\
\hline & & & & & \\
\hline Total & 32 & 13 & 08 & 05 & 01 \\
\hline
\end{tabular}

Table.3 Gender wise distribution of intestinal parasitic infections

\begin{tabular}{|l|c|c|c|}
\hline \multicolumn{1}{|c|}{ Parasite } & \multicolumn{2}{|c|}{ Gender } & \multirow{2}{*}{ Total } \\
\hline Entamoeba histolytica & 18 & Female & 33 \\
\hline Giardia lamblia & 9 & 15 & 16 \\
\hline Hymenoiepis nana & 1 & 7 & 3 \\
\hline Ascaris lumbricoides & 2 & 2 & 2 \\
\hline Strongyloides stercoralis & 1 & 0 & 2 \\
\hline Taenia species & 0 & 1 & 2 \\
\hline Enterobius vermicularis & 0 & 02 & 1 \\
\hline Total & 31 & 1 & 59 \\
\hline
\end{tabular}




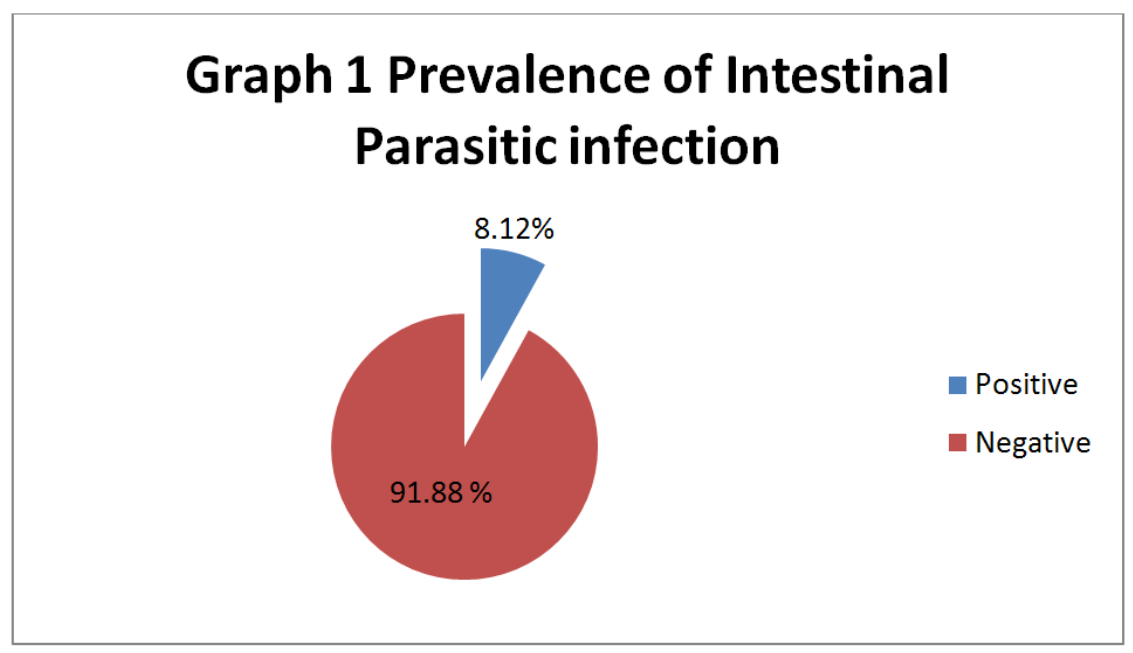

Figure.1 Larva of Strongyloides stercoralis 2. Trophozoite of Giardia lamblia 3. Egg of Enterobius vermicularis 4. Egg of Hymenolepis nana 5. Proglottid of Tapeworm 6. Adult worm of Enterobius vermicularis 7. Unfertilized egg of Ascaris 8. Fertilized egg of Ascaris lumbricoides 9\&10. Cyst of Entamoeba histolytica 11. Cyst of Giardia lamblia 12. Egg of Taenia species

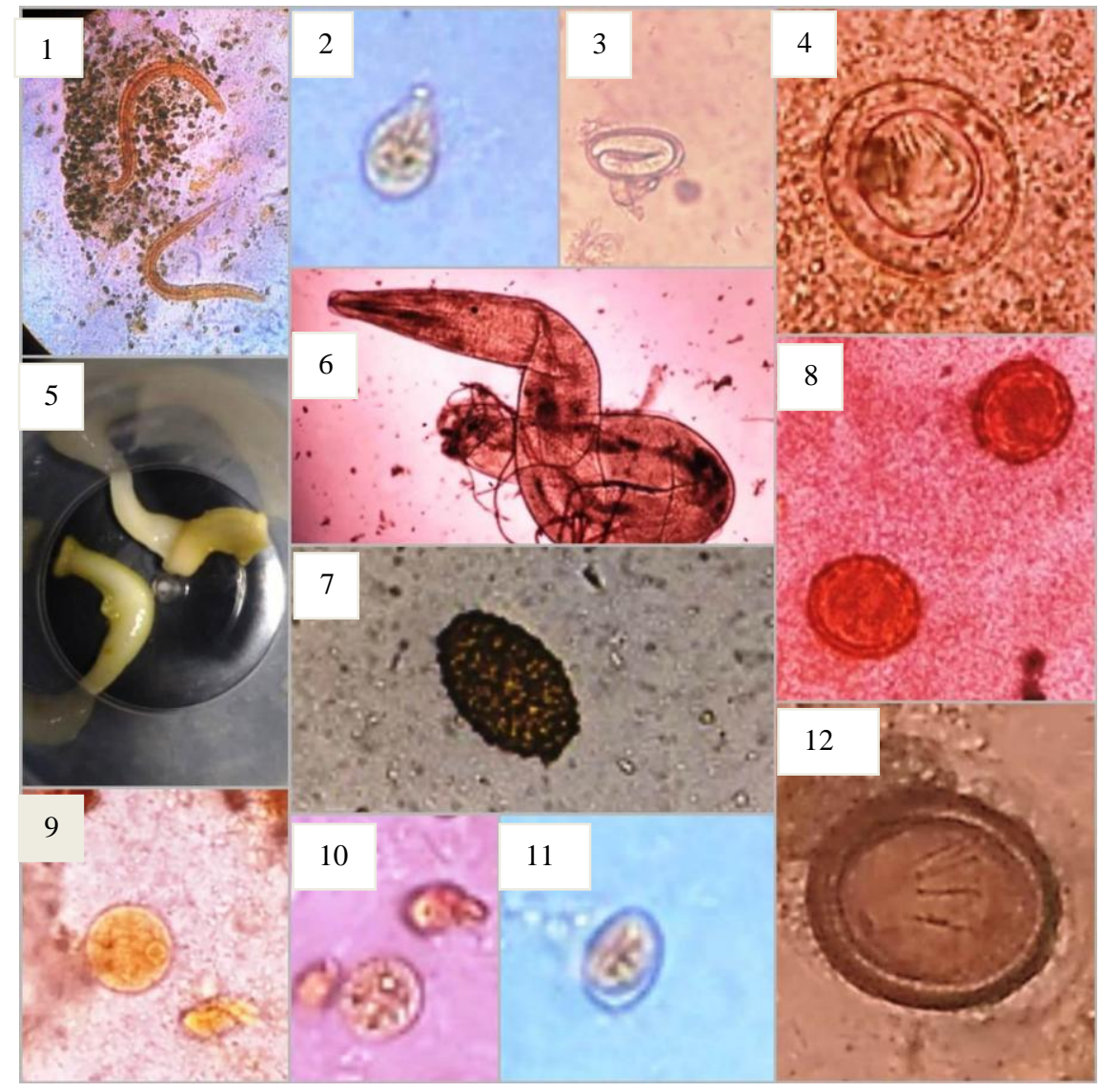


Parasitic infection is a matter of concern in a developing country like India, because it is endemic and its infection particularly in children can result in high morbidity and mortality. So knowledge about the intestinal parasites prevalent in that particular area is important for diagnosis and management. In the present study we have collected a data of 726 patients who were symptomatic as well as asymptomatic.

The prevalence of intestinal parasitic infections at our tertiary care hospital was $8.12 \%$ which is comparable with that of a study from conducted by Rajvir Singh et al., (6.68\%) and Anil kumar ${ }^{7}$ (9.21\%) from north India. And also result was similar with respect to detection rate among protozoa and helminths, Protozoa were being more, with highest detection of Entamoeba histolytica followed by Giardia lamblia (Anil kumar et al) and vice-versa in case of Rajvir Singh i.e., Highest Giardia followed by Entamoeba histolytica. The reason for highest protozoa could be due to periodic deworming which has taken care of helminths.

When compared to the study by Parameshwarappa et al., ${ }^{5}$ conducted at Kalaburagi showed higher prevalence rate of $27.6 \%$. The difference could be attributed to use of many concentration techniques which resulted in higher detection rates, inclusion of rural health centre and moreover the study was conducted 8-10 yrs back. The low prevalence rate in our study could be explained due to improvement in the sanitation, drinking water supply, personal hygiene, awareness and not including concentration techniques for diagnosis. Some similarities were seen like highest parasite found was Entamoeba histolytica followed by Giardia lamblia, however we could not detect Hookworm and Trichuris trichura egg in our study. To know the exact prevalence of intestinal parasitic infection of this region, further it requires population based prospective study.

Regarding age wise distribution of parasitic infections, most of the infections were seen in paediatric age group (Table 2) especially Giardia lamblia and Hymenolepis nana which was comparable with that of study from Moradabad $^{8}$, Parameshwarappa et al., ${ }^{5}$, Ismat rehana et al., ${ }^{1}$ There are variations in other studies where adults were more infected with parasites, so definitely this depends on various factors like personal hygiene, knowledge about hand hygiene, geographical area and health education.

With respect to gender wise distribution, males were most commonly infected compared to females (Table 3) which corroborated with the study conducted by Shyamal Kanti Pal et al., Ismat Rehana et al., Rajvir singh et al., ${ }^{6}$ Yogendra Pratap mathuria $^{8}$, Shrihari Narayan et al., ${ }^{9}$ Taruna singh et al., ${ }^{10}$.

No hookworm was detected from our study. This could be due to more use of footwear by labourers and farmers and decrease in the number of open defaecation in villages.

So the present study revealed the changing trends of intestinal parasitic infections which may be perhaps due to changes in socioeconomic status, availability of portable water, environmental sanitation and awareness.

In conclusion, prevalence of intestinal parasitic infection at a tertiary care hospital, Kalaburagi is $8.12 \%$. Entamoeba histolytica and Giardia lamblia are the most common parasitic infection in this place. The present study highlights the importance of knowledge of intestinal parasitic infections of particular region, which help the clinicians for diagnosis and management. Prevalence rate in our 
study was low which indicates that there is improvement in personal hygiene, drinking water supply and sanitary practices.

\section{References}

1. Ismat Rehana, Pragya Shakya, Seema Singh. Study of Intestinal Parasites in Patients attending a Tertiary Care Hospital in Western U.P., India. International journal of science and research 2017;6(5): 2116-2118

2. Shyamal Kanti Pal, Rituparna Bhattacharya, Promukh Bhattacharya, Uttam Kumar Paul. Intestinal parasitic infection in adult patients attending tertiary care hospitals: a retrospective study. International journal of advances in medicine 2017;4(5):1458-1462

3. Randhir Kumar, Priyanka Paul Biswas, Tarannum Yasmin, Aninda Sen et al., Prevalence of intestinal parasitic infections in patients attending a tertiary care hospital in eastern bihar. $J$ of Evolution of Med and Dent Sci 2014;3(24): 6740-6746

4. Bhattacharya Rituparna, P Bhattacharya, U K Paul, A Bandyopadhyay. Prevalence of Intestinal parasites in a tertiary care hospital in rural bihar. International journal of scientific study 2017;4(12):8993

5. Parameshwarappa KD, Chandrakanth $\mathrm{C}$, Sunil B. The prevalence of Intestinal parasitic infestations and the evaluation of different concentration techniques of the stool examination. Journal of clinical and diagnostic research 2012;6(7):1188-1191

6. Rajvir Singh, Pooja Singla, Madhu Sharma, Aparna. Prevalence of Intestinal Parasitic Infections in a Tertiary Care Hospital in Northern India: Five year retrospective study. Int.J.Curr.Microbiol.App.Sci (2013) 2(10): 112-117

7. Anil Kumar, Deepesh Kumar, Sujeet Kumar. Parasitic Infection: A Prevalence Study at a Tertiary Care Hospital .International Journal of Health Sciences \& Research 2016;6(1):154-157

8. Yogendra Pratap Mathuria, Archana Singh Prevalence of Intestinal Parasites at a Tertiary Care Centre at Moradabad, Western Uttar Pradesh, India: A One-Year Observational Study. Annals of International medical and dental research 2017;3(5):7-10

9. Narayan Shrihari, Kumudini T.S, Mariraj. J, Krishna. S The Prevalence of Intestinal Parasitic Infections in a Tertiary Care Hospital-a retrospective study. Journal of Pharmaceutical and Biomedical Sciences 2011;12(13):1-4

10. Taruna Singh, Ganesh S. Bhatambare, Arvind B. Deshmukh, Trupti Bajpai, Ila Srivastava et al., Study of the prevalence of intestinal parasitic infections in a tertiary care hospital located in central India. International Journal of Health System and Disaster Management 2014;2(2):113-116

\section{How to cite this article:}

Ravish Kumar, M., Praveen Kumar Doddamani, Prashant Parandekar and Prashant Kumar. 2019. Prevalence of Intestinal Parasitic Infections at a Tertiary Care Hospital: a Retrospective Study. Int.J.Curr.Microbiol.App.Sci. 8(06): 2822-2827. doi: https://doi.org/10.20546/ijcmas.2019.806.340 